\title{
AUTONOMIA PRIVADA COLETIVA
}

\author{
PRIVATE COLLECTIVE AUTONOMY
}

Walküre Lopes Ribeiro da Silva ${ }^{1}$

\begin{abstract}
Resumo:
A autonomia privada coletiva expressa o poder normativo dos grupos organizados. A globalização gera a flexibilização, que pode significar precariedade ou processo de adaptação à nova realidade. A ordem pública limita a flexibilização e a autonomia privada coletiva deve respeitar esses limites.

Palavras-chave: Autonomia privada coletiva. Pluralismo jurídico. Globalização. Ordem pública. Flexibilização de adaptações.
\end{abstract}

\begin{abstract}
:
Private collective autonomy expresses the normative power of organized groupes. Globalization generates flexibility that can signify precariousness or process of adaptation to the new reality. Public order limits flexibility and private collective autonomy must respect these limits.
\end{abstract}

Keywords: Private collective autonomy. Juridical pluralism. Globalization. Public order. Flexibility of adaptation.

\section{Pluralismo jurídico como pressuposto metodológico}

Inicialmente, cabe recordar que hoje se encontra difundido o entendimento de que o Direito do Trabalho se insere no contexto do pluralismo jurídico: enquanto ordenamento jurídico compõe-se de uma pluralidade de normas e também de uma pluralidade de fontes normativas. Sob a ótica das fontes, admite-se que tanto o Estado como os particulares elaboram normas jurídicas trabalhistas.

O Direito do Trabalho nasceu sob o impacto combinado da Revolução Industrial e da Revolução Francesa, que promoveram a transformação do modo de produção e o surgimento do Estado Liberal, marcado pela rarefação legal e pela proibição de ajustes coletivos, em virtude da concepção individualista em que se fundava. As terríveis condições de trabalho impostas pela indústria levaram os trabalhadores a se organizarem coletivamente para apresentar reivindicações aos empregadores, de início afrontando a lei e depois, com a ascensão do Estado intervencionalista, sob a proteção da lei. Essa atuação

\footnotetext{
1 Professora Titular do Departamento de Direito do Trabalho e da Seguridade Social da Faculdado de Direito da Universidade de São Paulo.
} 
coletiva foi responsável por criações originalíssimas do Direito do Trabalho: a greve e a negociação coletiva.

Reconhecida pelo ordenamento estatal em diferentes países, a partir do final do século passado, a atividade negocial das organizações de trabalhadores e de empregadores deu lugar a contratos coletivos de trabalho - entendidos em sentido genérico - que apresentam características contrárias ao dogma da vontade pregado pelo Iluminismo: destinam-se a regular as relações de trabalho em curso e as que venham a se construir durante a vigência, abrangendo em alguns modelos jurídicos sócios e não-sócios das entidades pactuantes. O efeito ultra partes e até erga omnes levou Raymond Saleilles a afirmar, já em 1901, que os atos jurídicos praticados por tais entidades não tinham do contrato senão o nome. ${ }^{2}$

Na primeira metade do século XX não foram poucos os doutrinadores que apontaram a existência de um sistema de relações coletivas de trabalho com estrutura organizativa permanente e conjunto de normas equiparável ao ordenamento da comunidade internacional: Léon Duguit, George Gurvitch, Hugo Sinzheimer etc. ${ }^{3}$

A noção de ordenamento jurídico surgiu no âmbito da teoria institucionalista, a qual combatia o monismo jurídico ao reconhecer que o Direito não é monopólio estatal, mas também resulta da atividade criadora das forças sociais organizadas. Santi Romano, em obra publicada em 1917 sob o título O ordenamento jurídico, afirmou que o Direito é instituição, entendida essa como a sociedade ordenada e organizada. ${ }^{4}$

De Santi Romano a Norberto Bobbio, passando por Hans Kelsen e Herbert Hart, assistimos ao deslocamento da concepção de ordenamento jurídico da ótica institucional para a normativa. Na brilhante crítica à teoria da instituição formulada por Bobbio em sua obra Teoria da norma jurídica, o Direito não pode ser reduzido ao aspecto institucional, pois não há organização sem normalização. Acrescentou ainda que a concepção do Direito como relação intersubjetiva também merece críticas, uma vez que apenas são jurídicas as relações regidas por pelo menos uma norma jurídica, constituindo as demais simples relações de fato. Assim, Bobbio concluiu que o direito objetivo compreende os aspectos da organização social, da intersubjetividade e da regulação, mas esse último

\footnotetext{
2 SALEILLES, Raymond. De la déclaration de volonté: contribution a l'étude de l'acte juridique dans le code civil allemand (art. 116 à 144). Paris: LGDJ, 1929. p. 229-230.

3 DUGUIT, Léon. Traité de droit constitutionnel. Paris: Ancienne Librairie Fontemoing \& Cie, 1921. p. 308; GURVITCH, Georges. Le temps présent et l'idée du droit social. Paris: Vrin, 1931. p. 41; SINZHEIMER, Hugo Apud GIUGNI, Gino. Introduzione allo studio della autonomia collettiva. Milano: Giuffrè, 1977. p. 23-24.

4 ROMANO, Santi. L'ordinamento giuridico. Firenze: Sansoni, 1951. p. 25-27.
} 
é o mais relevante por configurar condição necessária e suficiente para a formação de uma ordem jurídica, englobando os outros dois. Em obra posterior, Bobbio apresentou a teoria do ordenamento jurídico enquanto sistema normativo, por se ter convencido de que a norma isolada não explica o direito: anteriormente cuidara de analisar a árvore e deixara de ver a floresta. ${ }^{5}$

Essa concepção normativa é para nós o pressuposto metodológico do estudo da autonomia privada coletiva, conforme anunciamos já no início da exposição: trata-se de examinar a atuação normativa dos particulares, por meio de suas organizações representativas, na esfera das relações coletivas de trabalho, no contexto de um ordenamento que se apresenta como um sistema de normas oriundas de uma pluralidade de fontes, estatais e não-estatais.

2. Autonomia privada: poder originário ou poder derivado

Na perspectiva do pluralismo jurídico, em que coexistem fontes estatais e não-estatais, cabe indagar qual é a relação entre a autonomia privada - individual ou coletiva - e o Estado, ou seja, se aquela configura poder originário ou derivado relativamente a esse último.

Na obra Teoria de ordenamento jurídico, Norberto Bobbio explica que as normas tornam-se parte de um ordenamento jurídico mediante os mecanismos de recepção, se se tratar de norma elaborada por outro ordenamento, ou delegação do poder normativo por parte do poder supremo a poderes ou órgãos inferiores existentes no mesmo ordenamento. Daí surge a distinção entre fontes reconhecidas e fontes delegadas: a inserção da autonomia privada entre aquelas ou essas depende de sua consideração como um resíduo do poder normativo natural ou privado, antecedente ao Estado, na linha de pensamento de John Locke, ou como produto do poder originário do Estado, uma vez que ao criar o Estado os indivíduos teriam lhe transferido o poder normativo que detinham, na linha de pensamento de Thomas Hobbes. ${ }^{6}$

Adotando o escalonamento normativo (Stufenbau) de Kelsen, Bobbio argumenta que do mesmo modo que as normas de um ordenamento podem ser dispostas em ordem hierárquica, os vários ordenamentos que se relacionam entre si também podem ser hierarquizados, dando lugar a relações de coordenação ou de subordinação. E aponta,

\footnotetext{
5 BOBBIO, Norberto. Teoria della norma giuridica. Torino: Giappichelli, 1958. p. 17-23; 30-34. Id. Teoria dell'ordinamento giuridico. Torino: Giappichelli, 1960. p. 5.

6 Id. Teoria dell'ordinameno giuridico, cit., p. 26-29; 32-33.
} 
como exemplo dessas últimas, as relações entre o ordenamento estatal e os ordenamentos sociais, entre os quais está o sindical. Portanto, a autonomia privada coletiva, bem como a autonomia individual, configuram poder derivado do estatal, ou seja, fonte delegada. ${ }^{7}$

Também Luigi Ferri, em estudo dos anos 1950 que se tornou clássico, considera a autonomia privada um poder derivado, argumentando que constitui, sem dúvida, uma atividade que encontra sua fonte de validade nas normas estatais: o Estado determina negativamente o conteúdo das normas extra-estatais, ao subtrair à autonomia dos particulares certas matérias que reserva para sua própria atividade normativa. ${ }^{8}$

Ainda na década de 50, outro estudo essencial, embora menos conhecido entre nós, de autoria de Salvatore Romano, defendeu a autonomia privada como poder originário à luz da teoria institucionalista. Em primeiro lugar, observou que "o ordenamento privado, historicamente originário relativamente ao próprio ordenamento público, preexiste a esse e as suas criações são totalmente independentes e, às vezes, em nítido contraste com esse". Em segundo lugar, ressaltou que não cabe especial configuração do conceito de originariedade dos ordenamentos privados, se se aceitar a noção de instituição: esses ordenamentos são jurídicos pelo simples fato de existirem. Assim, o reconhecimento do ordenamento privado pelo estatal se dá no sentido lógico do termo, ou seja, se reconhece o que já existe e para atribuir ulteriores efeitos. ${ }^{9}$

3. Discussão sobre o poder normativo dos particulares no Direito do Trabalho

Na esfera trabalhista, o debate sobre a problemática do poder normativo dos particulares tem se centrado na análise da relação entre o Estado e a autonomia privada coletiva, dada a grande relevância da atuação coletiva de trabalhadores e de empregadores.

No Direito Comparado, cabem algumas observações quanto à Itália, berço da concepção de autonomia privada coletiva. Lá, a doutrina juslaboralista defende de modo consensual sua natureza de poder originário. Após a segunda guerra mundial, quando o modelo corporativista foi substituído pelo modelo democrático delineado na Constituição de 1948, os doutrinadores passaram a negar que a atuação normativa dos trabalhadores e dos empregadores, coletivamente organizados, se desse pela via da delegação do poder

7 BOBBIO, Norberto. Teoria della norma giuridica. Torino: Giappichelli, 1958. p. 17-23; 30-34. Id. Teoria dell'ordinamento giuridico. Torino: Giappichelli, 1960. p. 190-191.

8 FERRI, Luigi. L'autonomia privata. Milano: Giuffrè. 1959. p. 7.

9 ROMANO, Salvatore. Autonomia privata (Appunti). In: STUDI in onore di Francesco Messineo. Milano: Giuffré, 1959. v. 4, p. 352-354. 
normativo por parte do Estado, ao contrário da concepção sustentada no período fascista. A liberdade e a autonomia sindicais consagradas na nova Constituição, na medida em que propiciam uma visão conflitualista e não mais integrativa das relações de trabalho, justificavam essa nova posição doutrinária.

Em 1955, Ubaldo Prosperetti sintetizava essa nova visão ao afirmar: "não há dúvida de que os ordenamentos sindicais têm o caráter de ordenamentos originários mesmo relativamente ao ordenamentor estatal. (...) De resto, a originariedade dos ordenamentos sindicais com respeito àquele estatal manifesta-se claramente em todos aqueles casos de luta ou, de qualquer modo, de força sindical particularmente intensa, nos quais se costuma observar que existe um Estado dentro do Estado". ${ }^{10}$

$\mathrm{Na}$ América Latina, cujos ordenamentos jurídicos nacionais são marcados por forte intervencionismo estatal, a doutrina inclinou-se no passado à concepção de autonomia privada coletiva como poder derivado. Mas sempre houve exceções: entre os autores considerados clássicos, o mexicano Mário de la Cueva sustentou que, ao adotar posição intervencionista, o Estado foi pressionado a reconhecer a atividade negocial dos particulares, até então contra legem, de modo que trabalhadores e empregadores ou suas organizações representativas produzem normas "sem intervenção e mesmo contra a vontade do Estado". ${ }^{11}$

No Brasil, dado o papel predominante da lei na regulamentação do trabalho, em virtude tanto de sua inserção no sistema romano-germânico como da experiência corporativa, durante longo tempo a doutrina considerou a autonomia privada coletiva como poder derivado.

Porém, os anseios de modernização da legislação trabalhista têm conduzido a uma crescente valorização da autonomia privada coletiva, preconizando-se a mudança da relação entre as fontes do Direito do Trabalho. Nas palavras de Cássio Mesquita Barros, deve-se acabar com a premissa de que o Estado é a única fonte formal e colocar a autonomia privada coletiva no mesmo nível da produção normativa estatal. ${ }^{12}$

Essas idéias remetem à experiência italiana, onde a autonomia privada coletiva e o Estado, enquanto fontes normativas, ocupam o mesmo nível, de modo que, na relação entre os ordenamentos estatal e o particular, o princípio da norma mais favorável

\footnotetext{
${ }^{10}$ PROSPERETTI, Ubaldo. Preliminari sull'autonomia sindacale. Rivista di Diritto del Lavoro, Milano, anno 7, p. 160, 1955.

${ }^{11}$ CUEVA, Mario de la. El nuevo derecho mexicano del trabajo. México: Porrúa, 1977. p. 29.

${ }^{12}$ BARRoS, Cássio de Mesquita. O processo de globalização e o Direito do Trabalho. São Paulo: Centro Hispano-Brasileiro de Cultura; Faculdade Ibero-Americana, 1997. p. 19-20. (Cadernos Monográficos, 3).
} 
foi substituído pelo princípio da inderrogabilidade bilateral, com explícita proibição de derrogação in melius. Por outro lado, admite-se a flexibilização das normas legais ou convencionais mediante negociação coletiva, pelo uso da técnica da derrogação in pejus. ${ }^{13}$

Amauri Mascaro Nascimento, ao analisar a autonomia privada coletiva como fonte do Direito do Trabalho na América Latina, aponta que a hierarquia entre os ordenamentos começa a ser rediscutida na região com a flexibilização das relações de trabalho e que a própria noção de pluralidade de ordenamentos jurídicos sugere a existência de uma natural dinâmica nas relações entre os mesmos. ${ }^{14}$

4. Autonomia privada individual e coletiva, autonomia pública

Aspecto importante a ser considerado no estudo da autonomia privada coletiva é sua conceituação e distinção relativamente à autonomia privada individual e à autonomia pública. Comecemos por essa última.

Historicamente, a valorização da vontade como fonte de todo efeito jurídico, como força criadora de direitos e obrigações, foi proposta no século XVIII pelo Iluminismo, com fundamento em postulados jusracionalistas.

O Iluminismo forneceu as bases filosóficas para a Revolução Francesa. Com a vitória desta e sua repercussão em todo o mundo, o contrato tornou-se o instrumento tendencionalmente exclusivo de regulação das relações jurídicas. Afirmou-se a concepção de contrato como acordo ou encontro de vontades entre indivíduos livres e iguais.

Como resultado dessa concepção, verificou-se no plano jurídico a desconsideração das distinções e desigualdades reais, levada a extremos pelos pandectistas alemães do século XIX, que elaboraram o conceito de negócio jurídico como categoria mais geral, capaz de conter em si uma série de fenômenos mais ampla do que a contida no conceito de contrato, e por isso mesmo uma categoria mais abstrata, uma vez que para chegar a identificar aspectos comuns em fenômenos muito variados é necessário distanciarse deles no que tenham de concreto e específico. Essas características de generalidade e abstração evidenciam-se na definição de negócio jurídico como uma declaração de vontade dirigida a produzir efeitos jurídicos.

\footnotetext{
${ }^{13}$ ROMAGNOLI, Umberto. Diritto sindacale (storia del). In: DIGESTO delle discipline privatistiche: sezione commerciale. Torino: UTET, 1989. v. 4, p. 658.

14 NASCIMENTO, Amauri Mascaro. A autonomia coletiva como fonte de Direito do Trabalho na América Latina. LTr: revista legislação do trabalho, São Paulo, ano 59, n. 1, p. 17, jan. 1995.
} 
Como aponta Enzo Roppo, o negócio jurídico conseguiu operar “o máximo de unificação e igualização formal dos sujeitos jurídicos" ao apagar a concreta posição sócio-econômica das partes e os termos reais da troca econômica, atribuindo relevância exclusiva à vontade, de modo mais eficiente do que o contrato: enquanto esse "pressupõe uma duplicidade de sujeitos e evoca portanto uma atividade de troca econômica, o negócio jurídico é configurável como o ato de um só indivíduo, como manifestação solitária de sua vontade e, portanto, mais não evoca que a atividade de sua psique". ${ }^{15}$

Vê-se, pois, que tanto o contrato como o negócio jurídico propõem-se como resultados da autonomia da vontade. No século XX, surgiu a noção de autonomia privada, inicialmente na esfera individual e depois estendida pelos juslaboristas à esfera coletiva, como manifestação do poder de criar normas jurídicas atribuído aos particulares.

Cabe acrescentar que para grande parte da doutrina contemporânea a expressão autonomia da vontade é considerada sinônimo de autonomia privada, embora alguns apontem diferenças entre ambas. Sob a ótica da nomogênese jurídica, Francisco dos Santos Amaral Neto ressalta que "a autonomia da vontade tem uma conotação mais subjetiva, psicológica, enquanto a autonomia privada marca o poder da vontade de um modo objetivo, concreto e real'. Em outras palavras, enquanto a primeira destaca a formação e manifestação da vontade com vistas à prática de um ato jurídico, a segunda aponta para a vontade como expressão do poder dos particulares de criar normas jurídicas. ${ }^{16}$

Quanto à autonomia privada coletiva, Francesco Santoro-Passarelli ensina que o ordenamento jurídico reconhece aos grupos sociais intermediários o poder de regular os próprios interesses do mesmo modo que ocorre com os indivíduos singulares. Porém, a autonomia individual e a autonomia coletiva diferenciam-se quanto aos fins e à estrutura que comportam. ${ }^{17}$

Quanto aos fins, é possível afirmar que a autonomia individual visa a satisfazer interesse individual, pertinente à pessoa singularmente considerada, enquanto a autonomia coletiva visa a realizar interesse coletivo, pertinente ao grupo.

Quanto à estrutura, verifica-se que os limites internos e externos da autonomia são dados pelo grau de relevância dos interesses envolvidos, tanto privados

\footnotetext{
15 ROPPO, Enzo. O contrato. Tradução de Ana Coimbra e M. Januário C. Gomes. Coimbra: Almedina, 1988. p. 51.

${ }^{16}$ AMARAL NETO, Francisco dos Santos. A autonomia privada como princípio fundamental da ordem jurídica. Perspectivas estrutural e funcional. Boletim da Faculdade de Direito da Universidade de Coimbra, Coimbra, n. esp., estudos em homenagem ao Prof. Doutor Ferrer-Correia, v. 2, p. 14, 1989.
}

17 SANTORO-PASSARELLI, Francesco. Autonomia collettiva. In: Eugenio Jovene, 1961. v. 1, p. 261-262. 
- individual e coletivo - como públicos. Por isso mesmo deve ser explicada a distinção entre os três tipos de interesse: o coletivo diferencia-se do público por dizer respeito a um grupo de pessoas sem constituir interesse de toda a comunidade ou sociedade. Por outro lado, o interesse coletivo não se confunde com o individual, próprio das pessoas singularmente consideradas. ${ }^{18}$

Segundo Salvatore Pugliatti, interesses públicos são aqueles que dizem respeito à comunidade máxima, composta de indivíduos e grupos. Normalmente são considerados próprios do Estado, mas também podem ser atribuídos a agrupamentos tradicionais que representam a coletividade maior em âmbito mais restrito, como as regiões, os municípios etc. Assim, portadores típicos de interesses públicos são o Estado e as pessoas jurídicas públicas. O mesmo Autor esclarece que a expressão "interesse social" apresenta o caráter de um complexo de exigências da vida social que recaem tendencionalmente no campo dos interesses públicos. ${ }^{19}$

$\mathrm{Na}$ definição de Francesco Santoro-Passarelli, que se tornou clássica, o interesse coletivo é "o de uma pluralidade de pessoas por um bem idôneo apto a satisfazer uma necessidade comum. Este não é a soma dos interesses individuais, mas a sua combinação, e é indivisível, no sentido de que se satisfaz, não por muitos bens, aptos a satisfazerem necessidades individuas, mas por um único bem apto a satisfazer a necessidade da coletividade". ${ }^{20}$

Cabe acrescentar que a natureza do interesse em jogo distingue a autonomia privada - individual ou coletiva - da autonomia pública. Essa última, na definição de Guido Zanobini, é o poder atribuído aos entes públicos e aos próprios órgãos o Estado para emanar normas válidas no âmbito de competência respectivo, as quais integram o ordenamento estatal. A autonomia pública visa a satisfazer interesses públicos e duas diferenças inegáveis opõem-na à dos particulares: 1) a autonomia privada quase sempre se concretiza em negócios jurídicos bilaterais, enquanto a pública se expressa, na maioria das vezes, por intermédio de atos unilaterais da administração pública. Isso se deve à condição de igualdade entre os sujeitos no campo da autonomia privada e à condição de supremacia de que é investido um dos sujeitos na esfera da autonomia pública; 2) à parte os limites externos, constituídos nos dois casos pela lei, os limites internos são diversos: o particular

\footnotetext{
18 Id. Autonomia collettiva, giurisdizione, diritto di sciopero. In: 181.

19 PUGLIATTI, Salvatore. Diritto pubblico e diritto privato. In: ENCICLOPEDIA del diritto. Milano: Giuffrè, 1964. v. 12, p. 741-742.

20 SANTORO-PASSARELLI, Francesco. Nozioni di diritto del lavoro. Napoli: Eugenio Jovene, 1960. p. 21.
} 
dispõe de plena liberdade, nos limites da lei, lá onde o ente público goza daquela particular liberdade que se denomina discricionariedade. O ente público deve perseguir fins que não são escolhidos livremente por ele, mas que lhe são impostos pela lei, exercitando uma autonomia limitada à faculdade de escolher entre os vários meios possíveis. ${ }^{21}$

Amauri Mascaro Nascimento ensina que ainda não se determinou o sentido exato e definitivo da enunciação definitória da autonomia privada coletiva. Assim, há uma concepção restrita, que "significa o poder conferido aos representantes institucionais dos grupos sociais e de trabalhadores e de empregadores de criar vínculos jurídicos regulamentadores das relações de trabalho. A negociação coletiva é o seu procedimento de concretização. Os contratos coletivos de trabalho, expressão aqui tomada no sentido genérico, são o resultado da sua elaboração, o instrumento jurídico pelo qual se expressa e corporifica-se". Mas há ainda uma concepção ampla, como "princípio que fundamenta não só a negociação coletiva, mas, também, a liberdade sindical e a autotutela dos trabalhadores, sendo, sob essa visão, tríplice, portanto, a sua dimensão". ${ }^{22}$

Essa segunda concepção, mais abrangente, tornou-se consenso na doutrina italiana, nas palavras de Gino Giugni, por "haver interpretado e sistematizado de modo congruente a exigência de liberdade perante o Estado por parte dos grupos organizados, tal como se apresentou depois da queda do sistema corporativista. A importância desta concepção reside precisamente em haver conjugado liberdade e autonomia privada e em haver estendido os confins desta última ao fenômeno da autonomia coletiva. A noção de autonomia, por sua vez, é bivalente porque pressupõe a identificação de uma esfera de liberdade mas ao mesmo tempo o exercício de um poder de autoregulamentação". ${ }^{23}$

Em vários escritos importantes, posteriormente reunidos em livro, Francesco Santoro-Passarelli contribuiu notavelmente para a construção do conceito de autonomia privada coletiva vinculado não apenas à negociação coletiva mas também à liberdade sindical e à autotutela, à luz dos dispositivos da Constituição italiana de 1948 que, rompendo com a visão publicística do período fascista, promoveu a redemocratização daquele país, repondo o Direito do Trabalho no campo do direito privado. Cabe referência especial, sobretudo, a dois desses estudos: Autonomia collettiva e Autonomia collettiva,

\footnotetext{
${ }^{21}$ ZANOBINI, Guido. Autonomia pubblica e privata. In: Scritti vari di diritto pubblico. Milano: Giuffrè, 1955. p. 392.

${ }^{22}$ NASCIMENTO, Amauri Mascaro. Teoria geral do Direito do Trabalho. São Paulo: Saraiva, 1998. p. 125126.

${ }^{23}$ GIUGNI, Gino. Il diritto sindacale e i suoi interlocutori. Rivista Trimestrale di Diritto e Procedura Civile, Milano, ano 24, p. 388-389, 1970.
} 
giurisdizione, diritto di sciopero, recolhidos no volume primeiro dos Saggi di diritto civile. ${ }^{24}$

Outra contribuição notável para a afirmação da concepção mais ampla foi a de Ubaldo Prosperetti, ao vincular os aspectos normativo e institucional da autonomia privada: argumentou que a autonomia coletiva apresenta-se como normativa, quando analisada sob a ótica da elaboração de contratos coletivos de trabalho - em sentido genérico - por meio de negociação coletiva, mas que o termo autonomia vai além desse preciso e específico significado jurídico, pois diz respeito também a um fenômeno sociológico. Trata-se da denominada autonomia institucional, que se caracteriza "pelo fato de que o ordenamento se constitui por si, distinguindo-se, portanto, daqueles originados por iniciativa de outros, produzindo normas direta ou indiretamente relevantes para um outro ordenamento, considerado como superior no sentido de que se posiciona como qualificador do ordenamento apontado como autônomo (...) Aparece desse modo uma conexão de derivação entre autonomia institucional e autonomia normativa, que pode por hipótese caracterizar a autonomia sindical, tanto mais por que indica tratar-se de uma conexão necessária em um sistema de declarado reconhecimento por parte do Estado dos interesses coletivos profissionais mediante suas manifestações organizativas, segundo um princípio implícito nos ordenamentos estatais contemporâneos". ${ }^{25}$

5. Autonomia privada coletiva e intervencionismo estatal

A origem do fenômeno da autonomia privada coletiva está no século XVIII, na primeira Revolução Industrial. A nascente industrialização gerou a exploração da força de trabalho em proporções até então desconhecidas fora do regime da escravidão e levou os trabalhadores à revolta, primeiro de forma espontânea e desordenada, destruindo máquinas e instalações industriais, e depois de modo organizado, reunindo-se em entidades clandestinas que acabaram obtendo reconhecimento legal, quando o Estado adotou posição intervencionalista.

A intervenção do Estado nas relações de trabalho não esgotou a função da autonomia privada coletiva. Ficou evidente que o Estado não tem meios para regular minuciosamente as condições de trabalho em cada caso concreto e que o processo de elaboração das leis é mais lento e rígido do que o processo negocial. Portanto, o espaço

\footnotetext{
${ }^{24}$ SANTORO-PASSARELLI, Francesco. Autonomia collettiva, cit.; Id. Autonomia colletiva, giurisdizione, diritto di sciopero, cit.

25 PROSPERETTI, Ubaldo. op. cit. p. 158-159.
} 
conquistado à força pelos trabalhadores foi mantido mesmo com a atuação estatal, coexistindo no mesmo ordenamento jurídico normas estatais e negociais.

Contudo, nem sempre o intervencionismo apresenta-se como fator benéfico para a sociedade. A primeira metade do século XX foi marcada pela ascensão do corporativismo, que propôs um projeto orgânico de intervenção do Estado nas relações de trabalho. A lei italiana de 1926, que aparentemente disciplinava as relações coletivas de trabalho mas na realidade estruturava o Estado fascista, mostra com clareza os quatro pontos essenciais sobre os quais se fundamentava o projeto corporativista: 1) reconhecimento dos sindicatos como pessoas jurídicas de direito público; 2) eficácia substancialmente legislativa dos contratos coletivos estipulados pelas entidades sindicais; 3) solução de todos os conflitos coletivos de trabalho, jurídicos e econômicos, pela magistratura do trabalho; 4) proibição penal da greve. ${ }^{26}$

Portanto, o corporativismo caracteriza-se como um intervencionismo maléfico para a sociedade, na medida em que cerceia a liberdade sindical e submete os sindicatos ao Estado, que desempenha o papel de único dirigente da política sócioeconômica e árbitro supremo dos conflitos sociais.

Embora desde o início dos anos 30 o Brasil se dirigisse para o corporativismo, a Constituição de 1937 é o marco fundamental da opção por esse modelo. Do mesmo modo, embora desde o final da década de setenta o país já se encaminhasse para a redemocratização, a Constituição de 1988 é o marco essencial da ruptura com o modelo. Porém, o rompimento com o corporativismo não foi total, sobrevivendo no novo texto constitucional duas características centrais: a unicidade sindical e a contribuição sindical compulsória.

A modernização das relações de trabalho no Brasil passa necessariamente pela eliminação dessas duas características, sem o que estarão comprometidas a representatividade dos sindicatos e, consequentemente, a negociação coletiva e a concertação social por eles desenvolvidas, que constituem instrumentos fundamentais para a pretendida reestruturação da sociedade.

No plano ideológico, o corporativismo vincula-se ao totalitarismo, seja de direita seja de esquerda. Neste sentido igualam-se as experiências do Fascismo italiano, do Franquismo espanhol e do Socialismo Real do Leste europeu.

No segundo pós-guerra os países que vivenciaram o corporativismo romperam com o modelo e retomaram ou adotaram a democracia. Uma vez que é inerente

\footnotetext{
${ }^{26}$ ROMAGNOLI, Umberto. op. cit., p. 654.
} 
à concepção democrática a ampla participação dos interessados na tomada de decisões em todas as instâncias da vida social, os grupos afirmaram-se como atores principais no grande teatro da democracia, pois a organização coletiva provou ser o procedimento mais adequado para a representação de interesses perante o Estado.

A crescente relevância dos grupos nas sociedades democráticas levou Norberto Bobbio a afirmar que a representação de interesses cada vez mais se sobrepõe à representação política, processo que considera irreversível e exemplificado pelo fenômeno denominado neocorporativismo. ${ }^{27}$

O chamado neocorporativismo é característico dos Estados democráticos europeus e consiste na regulação das relações sociais mediante um procedimento negocial, no qual o Estado torna-se parte, inserindo-se em um contexto de concessões recíprocas. Estabelece-se assim uma relação triangular entre o Estado e as organizações privadas, sobretudo as representativas de empregadores e de trabalhadores, de modo que essas últimas tornam-se interlocutores privilegiados e depois exclusivos do primeiro, realizando uma negociação que se caracteriza como troca política. Essa troca tem por objetivo o consenso das decisões político-econômicas do Estado, o qual compensa a perda de parte de sua autoridade com a adesão dos membros dos grupos organizados à linha de atuação aprovada. $^{28}$

Portanto, o neocorporativismo distingue-se claramente do corporativismo. Nesse as organizações de trabalhadores e de empregadores tendem a integrar a própria estrutura do Estado e submetem-se às decisões tomadas unilateralmente por ele, enquanto naquele as organizações mantêm-se fora da estrutura estatal e participam em um plano de igualdade do processo decisório por serem reconhecidas pelo Estado como centros de referência social. ${ }^{29}$

Oneocorporativismo coloca os sindicatos diante do problema da participação. Diante da necessidade de compromisso entre os parceiros sociais e o Estado, surgiu a noção de participação conflitual, que procura conciliar o pressuposto de conflitualidade das relações de trabalho com a exigência de composição dos interesses.

Contudo, os sindicatos vêm sendo confrontados com a necessidade de aprofundar a experiência da participação em todas as esferas da vida social, da

\footnotetext{
${ }^{27}$ BOBBIO, Norberto. O futuro da democracia: uma defesa das regras do jogo. Trad. de Marco Aurélio Nogueira. Rio de Janeiro: Paz e Terra, 1986. p. 24-25.

${ }^{28}$ CESSARI, Aldo. Pluralismo, neocorporativismo, neocontratualismo. In: Rafaele. Dal garantismo al controllo. Milano: Giuffrè, 1987. p. 210.

29 Id. Ibid., p. 211-212.
} 
intraempresarial à estatal, diante da complexidade dos problemas da sociedade contemporânea, advindos da globalização da economia e das novas tecnologias.

\section{Autonomia privada coletiva, globalização e flexibilização}

A globalização configura um fenômeno complexo, podendo ser definida como "um conjunto de estruturas e processos econômicos e políticos derivados do caráter cambiante das mercadorias e bens que compõem a base da economia politica internacional - em particular, a diferenciação estrutural crescente dessas mercadorias e bens". Tal diferenciação estrutural promove a queda das fronteiras e resulta no enfraquecimento do Estado, na medida em que os agentes econômicos transnacionais ou multinacionais tornam-se capazes de tomar decisões autônomas em relação à vontade estatal. ${ }^{30}$

Também deve ser apontado que a globalização não é fenômeno apenas econômico, mas também cultural. Como ressalta Octavio Ianni, "o capitalismo se apresenta como um modo de produção e um processo civilizatório. Além de desenvolver e mundializar as suas forças produtivas e as suas relações de produção, desenvolve e mundializa instituições, padrões e valores sócio-culturais, formas de agir, sentir, pensar e imaginar". Como na base da globalização está o capitalismo, pode-se constatar a complexidade e a profundidade das transformações em curso. ${ }^{31}$

A globalização se dá no contexto do modo de produção capitalista e este intensificou e ampliou sua capacidade de atuação por meio das novas tecnologias, sobretudo a de base microeletrônica. Uma vez que a tecnologia "é o inevitável fundamento e condição da nossa existência na sociedade", o processo de globalização apresentase como irreversível e tem gerado a flexibilização do trabalho com vistas a ajustar as empresas à chamada competitividade internacional. ${ }^{32}$

Entretanto, a flexibilização do trabalho pode ser analisada sob dois ângulos diversos, como sinônimo de desregulação e precarização do contrato de trabalho ou como processo de adaptação do sistema de relações de trabalho à nova realidade econômicosocial. ${ }^{33}$

\footnotetext{
${ }^{30}$ CERNY, Philip G. Globalization and collective action. International Organization, Cambridge, v. 49, n. 4, p. 596-597, 1995.

31 IANNI, Octavio. A era do globalismo. Rio de Janeiro: Civilização Brasileira, 1996. p. 241.

${ }^{32}$ HELLER, Agnes. Por una teoria del valore. Roma: Editori Reuniti, 1980. p. 237.

33 SAPPIA, Jorge J. et al. Empleo y flexibilidad laboral. Buenos Aires: Astrea, 1996. p. 2.
} 
Tem prevalecido a desregulação e precarização do contrato de trabalho como meio de aumentar a competitividade e reduzir o desemprego provocado pela introdução das novas tecnologias e outros fatores.

Como relata André Gorz, as empresas promovem a flexibilização do trabalho em dois níveis: "o núcleo estável do pessoal da firma deve ter uma flexibilidade funcional; a mão-de-obra periférica, por seu lado, deve apresentar uma flexibilidade numérica. Em outros termos, em torno de um núcleo de trabalhadores estáveis, apresentando um amplo leque de qualificações, flutua uma mão-de-obra periférica, de qualificações menores e mais limitadas, submetidas ao acaso da conjuntura". ${ }^{34}$

À vista desses elementos, defendemos a flexibilização como processo de adaptação do sistema de relações de trabalho. Jean-Claude Javillier aponta argutamente que "a flexibilidade da adaptação existe há longo tempo. As regras do Direito do Trabalho tiveram que ser adaptadas aos particularismos profissionais e técnicos". ${ }^{35}$

Portanto, o Direito do Trabalho sempre conheceu uma flexibilidade da proteção normativa. Todavia, as novas formas de flexibilização colocam em xeque o princípio protetor. Uma vez que o trabalho não é mercadoria e o ser humano não se reduz a mera peça da engrenagem produtiva, devem ser reavaliadas as experiências de desregulação.

Embora o Direito sofra a influência da Economia, o inverso também é verdadeiro: desde suas origens, o Direito do Trabalho tanto suporta o impacto da realidade econômica como interfere na produção e distribuição de bens e serviços. Jean-Claude Javillier destaca que as considerações de ordem jurídica não devem ceder ao imperativo econômico, como pregam alguns, pois isso implicaria o desaparecimento de toda ação normativa e levaria à insegurança nas relações intersubjetivas. Devem ser estabelecidas prioridades e "da distinção entre o essencial e o acessório para o homem, o absoluto e o relativo no direito, há de resultar uma nova dinâmica do direito internacional do trabalho, dos direitos nacionais e dos sistemas de relações do trabalho". ${ }^{36}$

Qualquer que seja a posição adotada relativamente à flexibilização, a favor ou contra, salta à vista a relevância da autonomia privada na derrogação das normas estatais. Os defensores da flexibilização dividem-se entre os que preconizam um modelo

${ }^{34}$ GORZ, Andrè. Métamorphoses du travail: critique de la raison économique. Paris: Éditions Galilée, 1991. p. 89.

${ }^{35}$ JAVILLIER, Jean-Claude. Ordre juridique, relations professionnelles e flexibilité: approaches comparatives et internationales. Droit Social, Paris, n. 1, p. 64, janv. 1986.

${ }^{36}$ Id. Pragmatismo e inovación en el derecho del trabajo: reflexiones de un especialista en derecho del trabajo. Revista Internacional del Trabajo, Ginebra, v. 113, n. 4, p. 558, 1994. 
individualista, de retorno ao contrato de trabalho, e os que propõem um modelo coletivista, em que disposições convencionais substituiriam as legais.

No segundo modelo, somente poderiam ser estabelecidas condições de trabalho menos favoráveis do que as previstas em lei mediante negociação coletiva. É o que dispõe a Constituição brasileira no art. $7^{\circ}$, inciso VI, quanto à redução de salário.

Outros dispositivos constitucionais consagram o princípio da flexibilização no ordenamento jurídico brasileiro: a compensação de horários e a redução da jornada (art. $7^{\circ}$, inciso XIII) e a alteração da jornada no caso específico de trabalho realizado em turnos de revezamento (art. $7^{\circ}$, incisivo XIV) podem ser efetuadas mediante convenção ou acordo coletivo de trabalho.

À luz da Constituição de 1988 sustenta-se que está derrogado o art. 503 da Consolidação da Leis de Trabalho, por permitir a redução dos salários por iniciativa unilateral do empregador, sem negociação coletiva. Em todo caso, os exemplos supracitados mostram que o debate sobre flexibilização no Brasil não está confinado ao plano teórico e apontam a opção do legislador prático pelo modelo coletivista.

Observamos que o modelo individualista é menos defensável do que o coletivista, uma vez que fecha os olhos à realidade do vinculo empregatício, em que o empregado se encontra em posição de inferioridade econômica e subordinação jurídica perante o empregador. Por outro lado, despreza a ascensão da autonomia privada coletiva, cujo desenvolvimento extravasou a esfera trabalhista: a representação coletiva torna-se cada vez mais importante também em outras áreas do direito privado, notadamente no direito do consumo e no direito do meio ambiente.

\section{Ordem pública e flexibilização}

Lembramos que os críticos da flexibilização apontam suas dúvidas quanto ao papel da desregulação do Direito do Trabalho, perguntando se se trata de lutar contra a hiperregulamentação e a inflação de leis ou de colocar em xeque as intervenções do Estado na vida social. Apresenta-se aqui o debate sobre o papel e o alcance da ordem publica na esfera trabalhista.

Primeiramente, recordamos que a expressão ordem pública aparece pela primeira vez no Código Civil napoleônico. Não se trata de uma referência à clássica dicotomia Direito Público e Direito Privado, exprimindo ao contrário as idéias e os valores sobre os quais se fundamenta e se ordena a sociedade e que devem ser defendidos e conservados. Portanto, esta função de limite que a ordem pública desempenha no confronto 
com a autonomia negocial não configura "a exigência de supremacia do interesse público sobre o interesse dos particulares e a possibilidade de que este pode e deve curvar-se àquele, quando a situações concretas o exijam; a ordem pública, como limite da atuação negocial, exprime mais especificamente a exigência de que os particulares, com suas convenções, não subvertam aqueles valores fundamentais sobre os quais se estrutura a sociedade". (grifo nosso). ${ }^{37}$

Os valores e princípios fundamentais do ordenamento jurídico manifestamse tanto por meio de normas imperativas como de normas programáticas, concretizando "aqueles ideais de liberdade e de democracia que permitem à esfera dos interesses particulares coexistir e coordenar-se (sem ser sufocada) com a esfera dos interesses sociais", de modo que os dois tipos de interesse "encontram razões e instrumentos para um recíproco reforçamento". ${ }^{38}$

No campo das relações de trabalho, o legislador assegura aos trabalhadores um patamar de direitos, tendo à vista a dignidade e o valor do trabalho humano. Assim, a primeira função da ordem pública é promover a regulação social, impedindo retrocessos na sociedade. ${ }^{39}$

Entretanto, há os que distinguem a ordem pública no sentido do Direito do Trabalho da ordem pública geral. As normas imperativas decorrentes da primeira são relativamente inderrogáveis, permitindo-se sua substituição por outra que disponha de modo mais favorável ao trabalhador, em virtude do princípio tutelar ou protetor. As normas cogentes derivadas da ordem pública geral têm inderrogabilidade absoluta, de modo que a negociação de certas vantagens ou garantias está fora do campo da autonomia privada. Surge aqui a segunda função da ordem pública: “conferir o caráter intangível aos princípios superiores e às instituições fundamentais". ${ }^{40}$

Pedro Vidal Neto defende posição original quanto ao problema da inderrogabilidade das normas jurídicas trabalhistas, por força da atuação do princípio da norma mais favorável: "é próprio do Direito do Trabalho que as normas mais gerais e abstratas estabeleçam direitos que constituem um mínimo de garantias, sem proibir que as normas de categoria inferior, sobretudo as de origem convencional os dilatem. Nesse

\footnotetext{
${ }^{37}$ FERRI, Giovanni B. Ordine pubblico (dir. priv.) In: ENCICLOPEDIA del Diritto. Milano: Giuffrè, 1980. v. 30, p. 1.053 .

38 Id. Ibid., p. 1.054.

39 BONNECHÈRE, Michele. Les tendances à la dérèglementation et leur incidence sur la theorie des sources en droit du travail. Droit Social, Paris, n. 1, p. 45, janv. 1990.

${ }^{40}$ Id. loc. cit.
} 
caso, o que se aplica é a norma mais completa, elaborada dentro dos limites traçados pelas normas mais gerais e abstratas". ${ }^{41}$

Assim, não haveria a substituição de uma norma por outra, como sustenta Bonnechère, mas a aplicação de ambas, pois a norma mais favorável de categoria inferior contém em si as condições previstas em normas de categoria superior. Seguindo este raciocínio, não há inderrogabilidade relativa; esta será sempre absoluta, uma vez que tanto a norma mais favorável como a menos favorável são aplicadas, pois uma está contida na outra.

À vista do exposto, concluímos que só é possível efetuar a flexibilização do Direito do Trabalho se respeitados os limites impostos pela ordem pública, claramente expressos na Constituição de 1988. O art. 3º, I, propõe a construção de uma sociedade livre, justa e solidária como um dos objetivos fundamentais da República Federativa do Brasil. O art. 193, relativo à ordem social, estipula que essa "tem como base o primado do trabalho e como o objetivo o bem-estar e a justiça social". O art. 170, por sua vez, dispõe que "a ordem econômica, fundada na valorização do trabalho humano e na livre iniciativa, tem por fim assegurar a todos existência digna, conforme os ditames da justiça social (grifo nosso)".

A não ser que sejam alterados os valores e princípios sobre os quais se fundamenta a sociedade brasileira, a flexibilidade laboral não pode implicar pura e simplesmente a estipulação das condições de trabalho segundo as leis do mercado, sem considerar a dignidade do trabalho e da pessoa que o executa. Até porque é impossível dissociar o sujeito do objeto do contrato de trabalho, como reconheceram numerosos doutrinadores. Nas palavras magistrais de Alain Supiot, "a pessoa física constitui o objeto da prestação laboral. O corpo é o lugar, a passagem compulsória para o cumprimento das obrigações do trabalhador, é a própria coisa que forma a matéria do contrato. Falar do caráter pessoal da relação de trabalho é por sua vez ambíguo, perigoso e insuficiente". ${ }^{42}$

A flexibilização do Direito do Trabalho deve implicar a reestruturação da sociedade em sentido positivo. Ao invés de retroagir aos ideais iluministas, voltando a defender a auto-regulamentação do mercado, deve-se combinar a ação do Estado e a atuação dos particulares: ao contrabalançar o intervencionismo estatal com a autonomia coletiva, corrigem-se as distorções do mercado.

Evidencia-se, então, a necessidade de manter regras e princípios jurídicos

\footnotetext{
${ }^{41}$ VIDAL NETO, Pedro. Fontes do Direito do Trabalho. In: MAGANO, Octavio Bueno (Coord.). Curso de Direito do Trabalho em homenagem a Mozart Victor Russomano. São Paulo: Saraiva, 1985. p. 105-121.

${ }^{42}$ SUPIOT, Alain. Critique du droit du travail. Paris: PUF, 1994. p. 59-60.
} 
fundamentados na ordem pública, que reflitam valores considerados essenciais para o bom funcionamento da sociedade e não-submetidos à lei do mercado, e de utilizar a negociação coletiva como instrumento de adaptação do sistema de relações de trabalho, em um quadro legal de plena liberdade sindical.

São Paulo, dezembro de 2007.

\section{Referências}

AMARAL NETO, Francisco dos Santos. A autonomia privada como princípio fundamental da ordem jurídica. Perspectivas estrutural e funcional. Boletim da Faculdade de Direito da Universidade de Coimbra, Coimbra, n. esp., estudos em homenagem ao Prof. Doutor Ferrer-Correia, v. 2, p. 5-41, 1989.

BARroS, Cássio de Mesquita. O processo de globalização e o Direito do Trabalho. São Paulo: Centro Hispano-Brasileiro de Cultura; Faculdade Ibero-Americana (Cadernos Monográficos, 3), 1997.

BOBBIO, Norberto. O futuro da democracia: uma defesa das regras do jogo. Trad. de Marco Aurélio Nogueira. Rio de Janeiro: Paz e Terra, 1986.

. Teoria della norma giuridica. Torino: Giappichelli, 1958.

. Teoria dell'ordinamento giuridico. Torino: Giappichelli, 1960.

BONNECHÈRE, Michele. Les tendances à la dérèglementation et leur incidence sur la theorie des sources en droit du travail. Droit Social, Paris, n. 1, p. 40-48, janv. 1990.

CERNY, Philip G. Globalization and collective action. International Organization, Cambridge, v. 49, n. 4, p. 595-625, 1995.

CESSARI, Aldo. Pluralismo, neocorporativismo, neocontratualismo. In: ; DE LUCA TAMAJO, Rafaele. Dal garantismo al controllo. Milano: Giuffrè, p. 203-236, 1987.

CUEVA, Mario de la. El nuevo derecho mexicano del trabajo. México: Porrúa, 1977.

DUGUIT, Léon. Traité de droit constitutionnel. Paris: Ancienne Librairie Fontemoing \& Cie, 1921.

FERRI, Giovanni B. Ordine pubblico (dir. priv.) In: ENCICLOPEDIA del Diritto. Milano: Giuffrè v. 30, p. 1038-1057, 1980. 
FERRI, Luigi. L'autonomia privata. Milano: Giuffrè. 1959.

GIUGNI, Gino. II diritto sindacale e i suoi interlocutori. Rivista Trimestrale di Diritto e Procedura Civile, Milano, ano 24, p. 369-406, 1970.

. Introduzione allo studio della autonomia collettiva. Milano: Giuffrè, 1977.

GORZ, Andrè. Métamorphoses du travail: critique de la raison économique. Paris: Éditions Galilée, 1991.

GURVITCH, Georges. Le temps présent et l'idée du droit social. Paris: Vrin, 1931.

HELLER, Agnes. Por una teoria del valore. Roma: Editori Reuniti, 1980.

IANNI, Octavio. A era do globalismo. Rio de Janeiro: Civilização Brasileira, 1996.

JAVILLIER, Jean-Claude. Ordre juridique, relations professionnelles e flexibilité: approaches comparatives et internationales. Droit Social, Paris, n. 1, p. 56-65, janv. 1986.

. Pragmatismo e inovación en el derecho del trabajo: reflexiones de un especialista en derecho del trabajo. Revista Internacional del Trabajo, Ginebra, v. 113, n. 4, p. 551-569, 1994.

NASCIMENTO, Amauri Mascaro. A autonomia coletiva como fonte de Direito do Trabalho na América Latina. LTr: revista legislação do trabalho, São Paulo, ano 59, n. 1, p. 11-18, jan. 1995.

. Teoria geral do Direito do Trabalho. São Paulo: Saraiva, 1998.

PROSPERETTI, Ubaldo. Preliminari sull'autonomia sindacale. Rivista di Diritto del Lavoro, Milano, anno 7, p. 158-168, 1955.

PUGLIATTI, Salvatore. Diritto pubblico e diritto privato. In: ENCICLOPEDIA del diritto. Milano: Giuffrè v. 12, p. 696-746, 1964.

ROMAGNOLI, Umberto. Diritto sindacale (storia del). In: DIGESTO delle discipline privatistiche: sezione commerciale. Torino: UTET, v. 4, p. 651-658, 1989.

ROMANO, Salvatore. Autonomia privata (Appunti). In: STUDI in onore di Francesco Messineo. Milano: Giuffré, v. 4, p. 327-444, 1959.

ROMANO, Santi. L'ordinamento giuridico. Firenze: Sansoni, 1951.

ROPPO, Enzo. O contrato. Trad. de Ana Coimbra e M. Januário C. Gomes. Coimbra: Almedina, 1988. 
SALEILLES, Raymond. De la déclaration de volonté: contribution a l'étude de l'acte juridique dans le code civil allemand (art. 116 à 144). Paris: LGDJ, 1929.

SANTORO-PASSARELLI, Francesco. Autonomia collettiva. In: . Saggi di diritto civile. Napoli: Eugenio Jovene. v. 1, p. 177-204, 1961.

. Autonomia collettiva, giurisdizione, diritto di sciopero. In: Saggi di diritto civile. Napoli: Eugenio Jovene, v. 1, p. 255-266, 1961. . Nozioni di diritto del lavoro. Napoli: Eugenio Jovene, 1960.

SAPPIA, Jorge J. et al. Empleo y flexibilidad laboral. Buenos Aires: Astrea, 1996.

SUPIOT, Alain. Critique du droit du travail. Paris: PUF, 1994.

VIDAL NETO, Pedro. Fontes do Direito do Trabalho. In: MAGANO, Octavio Bueno (Coord.). Curso de Direito do Trabalho em homenagem a Mozart Victor Russomano. São Paulo: Saraiva, p. 105-121.

ZANOBINI, Guido. Autonomia pubblica e privata. In: Scritti vari di diritto pubblico. Milano: Giuffrè, 1955. p. 391-396. 1985. 


\section{APÊNDICE 1}

Lista das organizações européias de parceiros sociais consultadas em conformidade com o artigo 138

1. Organizações interprofissionais de carácter geral

- União das Confederações da Indústria e dos Empregadores da Europa (UNICE)

- Centro europeu das empresas de participação pública e das empresas de interesse económico geral (CEEP)

- Confederação Europeia dos Sindicatos (CES)

2. Organizações interprofissionais que representam determinadas categorias de trabalhadores ou de empresas

- União Europeia do Artesanato e das Pequenas e Médias Empresas (UEAPME)

- Confederação Europeia dos Quadros Técnicos (CEC).

- Eurocadres

3. Organizações específicas

- EUROCHAMBRES (Associação Europeia de Câmaras de Comércio e Indústria)

4. Organizações sectoriais representativas dos empregadores

- Associação Internacional dos Aeroportos Civis - Região Europeia (ACI-Europe)

- Associação de Agentes de Seguros Cooperativos e Mutualistas Europeus (ACME)

- Associação dos operadores de redes de telecomunicações (ETNO)

- Associação dos operadores postais públicos europeus (POSTEUROP)

- Associação das organizações nacionais de empresas de pescas da União Europeia (EUROPECHE)

- Associação dos produtores europeus de potássio (APEP)

- Organização Europeia da Marinha Mercante (OEB)

- Associação das Transportadoras Aéreas Europeias (AEA)

- Associação Internacional de Intermediários de Seguros e Resseguros (BIPAR)

- Comité Europeu dos Seguros (CEA)

- Comité Europeu dos Combustíveis Sólidos (CECSO) 
- Comité Europeu de Produtores de Açúcar (CEFS)

- Comité Geral da Cooperação Agrícola da União Europeia (COGECA)

- Comunidade de Caminhos-de-ferro Europeus (CCFE)

- Confederação das Associações Nacionais de Curtidores e Surradores da Comunidade Europeia (COTANCE)

- Confederação das Organizações Profissionais Agrícolas da União Europeia (COPA)

- Federação Europeia da Indústria do Calçado (CEC)

- Confederação Europeia das Indústrias da Madeira (CEI-Madeira)

- Confederação Europeia das Organizações Patronais de Cabeleireiros (CIC-Europa)

- Confederação Europeia dos Serviços de Segurança (CoESS)

- Confederação Internacional das Empresas de Trabalho Temporário (CIETT-Europa)

- Associações de Armadores da Comunidade Europeia (ECSA)

- European Cockpit Association (ERA)

- Federação Bancária da União Europeia (FBE)

- Federação Europeia da Indústria da Construção (FIEC)

- Federação Europeia da Indústria da Limpeza (FENI)

- Grupo Empregadores das Organizações Profissionais Agrícolas da CE (GEOPA)

- Grupo Europeu das Cooperativas Bancárias (GEBC)

- Grupo Europeu dos Bancos de Poupança (GECE)

- Confederação das associações nacionais da hotelaria e restauração da Comunidade Europeia (HOTREC)

- International Underwriters Association (IACA)

- Liga europeia das associações de empresários do espectáculo (PEARLE*)

- Organização europeia dos têxteis e do vestuário (EURATEX)

- Representação junto da UE do comércio grossista, retalhista e internacional (EUROCOMMERCE)

- União europeia dos fabricantes de móveis (UAE)

- União Internacional da Navegação Fluvial (UINF)

- União Internacional dos Transportes Rodoviários, IRU

- Comité europeu das empresas de electricidade (EURELECTRIC)

5. Federações sindicais europeias

- Aliança europeia do espectáculo (EEA)

- European Cockpit Association (ECA) 
- Federação europeia dos sindicatos das minas, da indústria química e da energia (EMCEF)

- Federação europeia dos sindicatos dos sectores da alimentação, agricultura, turismo e ramos conexos (EFFAT)

- Federação Europeia dos Trabalhadores dos Transportes (ETF)

- Federação europeia dos trabalhadores da construção e madeira (FETBB)

- Federação sindical europeia dos serviços públicos (FSESP)

- Federação sindical europeia dos têxteis, vestuário e cortumes (FSE:THC)

- Union Network International - (UNI-Europa)

- Comité sindical europeu da educação $(\mathrm{CSEE})(*)$

- Federação Europeia dos Jornalistas (FEJ) (*)

- Federação Europeia dos Metalúrgicos (FEM) (*)

A lista será actualizada à medida que forem sendo criados novos comités de diálogo social sectorial elou tendo em conta os resultados do estudo de representatividade.

(*) Federações filiadas na CES, recebem cópia para informação

Fonte: <http://eur-lex.europa.eu/LexUriServ/site/pt/com/2002/com2002_0341pt01.doc>. Acesso em: 02 maio 2007 


\section{APÊNDICE 2}

Lista dos comitês setoriais de diálogo social

\begin{tabular}{|c|c|c|c|}
\hline Setor & Trabalhadores & Empregadores & Data de Criação \\
\hline Agricultura & EFFAT & GEOPA-COPA & \\
\hline Mobiliário & FETBB & UEA & \\
\hline Seguros & UNI-Europa & ACME; BIPAR; CEA & \\
\hline Aviação civil & ECA; ETF & $\begin{array}{l}\text { ACI Europe; AEA; ERA; } \\
\text { IACA }\end{array}$ & \\
\hline Bancos & UNI-Europa & FBE; GEBC; GECE & \\
\hline Madeira & FETBB & CEI-Bois & \\
\hline Calçado & FSE-THC & CEC & \\
\hline Caminhos-de-ferro & ETF & CCFE & \\
\hline Comércio & UNI-Europa & EUROCOMMERCE & \\
\hline Construção & FETBB & FIEC & \\
\hline Cultura & EEA & PEARLE* & \\
\hline Electricidade & EMCEF; FSESP & EURELECTRIC & \\
\hline Horeca/turismo & EFFAT & HOTREC & \\
\hline Trabalho temporário & UNI-Europa & CIETT Europe & \\
\hline Minas & EMCEF; & APEP; CECSO & \\
\hline Navegação interna & ETF & OEB; UINF & \\
\hline Limpeza & UNI-Europa & FENI & \\
\hline Pesca de mar & ETF & EUROPESCAS / COGECA : & \\
\hline Correios & UNI-Europa & POSTEUROP & \\
\hline Segurança privada & UNI-Europa & CoESS & \\
\hline Serviços pessoais & UNI-Europa & CIC Europe & \\
\hline Açúcar & EFFAT & CEFS & \\
\hline Curtumes & FSE-THC & COTANCE & \\
\hline Telecomunicações & UNI-Europa & ETNO & \\
\hline Têxteis e vestuário & FSE-THC & EURATEX & \\
\hline Transporte marítimo & ETF & ECSA & \\
\hline $\begin{array}{l}\text { Transportes } \\
\text { rodoviários }\end{array}$ & ETF & IRU & \\
\hline
\end{tabular}

Fonte: <http://eur-lex.europa.eu/LexUriServ/site/pt/com/2002/com2002_0341pt01.doc>. Acesso em: 02 maio 2007 


\section{APÊNDICE 3}

The sectoral social dialogue committees

\begin{tabular}{|c|c|c|c|}
\hline Sectors & $\begin{array}{c}\text { Employees' } \\
\text { organisations }\end{array}$ & Employers' organisations & Date of creation \\
\hline Agriculture & EFFAT & GEOPA/COPA & 1999 \\
\hline Audiovisual & $\begin{array}{c}\text { EFJ, EURO-MEI, } \\
\text { FIA. FIM }\end{array}$ & $\begin{array}{l}\text { ACT, AER, CEPI, EBU, } \\
\text { FIAPF }\end{array}$ & 2004 \\
\hline Banking & UNI-Europa & EACB, ESBG, FBE & 1999 \\
\hline Civil aviation & ECA, ETF & $\begin{array}{l}\text { ACIEUROPE, AEA, } \\
\text { CANSO, ERA, IACA }\end{array}$ & 2000 \\
\hline Cleaning industry & UNI-Europa & EFCI & 1999 \\
\hline Commerce & UNI-Europa & EuroCommerce & 1999 \\
\hline Construction & EFBWW & FIEC & 1999 \\
\hline Electricity & EMCEF, EPSU & EURELECTRIC & 2000 \\
\hline Footwear & ETUF:TCL & $\mathrm{CEC}$ & 1999 \\
\hline Furniture & EFBWW & UEA & 2001 \\
\hline Horeca & EFFAT & HOTREC & 1999 \\
\hline Inland waterways & ETF & EBU, ESO & 1999 \\
\hline Insurance & UNI-Europa & ACME, BIPAR, CEA & 1999 \\
\hline Live performance & EAEA & PEARLE & 1999 \\
\hline $\begin{array}{l}\text { Local \& regional } \\
\text { government }\end{array}$ & EPSU & CEMR & 2004 \\
\hline Mines & EMCEF & $\begin{array}{l}\text { APEP, Euracoal, } \\
\text { Euromines, IMA }\end{array}$ & 2002 \\
\hline Personal services & UNI-Europa & EU Coiffure & 1999 \\
\hline Postal services & UNI-Europa & PostEurop & 1999 \\
\hline Private security & UNI-Europa & CoESS & 1999 \\
\hline Railways & ETF & CER & 1999 \\
\hline Road transport & ETF & IRU & 1999 \\
\hline Sea fishing & ETF & EUROPECHE/COGECA & 1999 \\
\hline Sea transport & ETF & ECSA & 1999 \\
\hline Shipbuilding & EMF & CESA & 2003 \\
\hline Sugar & EFFAT & CEFS & 1999 \\
\hline Tanning and leather & ETUF:TCL & COTANCE & 2001 \\
\hline Telecommunications & UNI-Europa & ETNO & 1999 \\
\hline Temporary work & UNI-Europa & Euro CIETT & 2000 \\
\hline Textile and clothing & ETUF:TCL & EURATEX & 1999 \\
\hline Woodworking & EFBWW & CEI-Bois & 2000 \\
\hline
\end{tabular}

Fonte: <http://eur-lex.europa.eu/LexUriServ/site/pt/com/2004/com2004_0557pt01.doc>. Acesso em: 02 maio 2007 